\title{
The Anatolian Journal of Cardiology
}

\section{Anatol J Cardiol • Volume 25 • Issue 7 • July 2021}

\section{Editor-in-Chief}

Çetin Erol

\section{Editors}

Cem Barçın

Asife Şahinarslan

Advisory Board of This Issue Mehmet Akboğa

Alper Akın

Yeşim Akın

Firdevs Aktaş

Özgür Aslan

Canan Ayabakan

Saide Aytekin

Macit Bitargil

Şahin Bozok

Özlem Mehtap Bostan

Başar Candemir

Uğur Canpolat

Uğur Coşkun

Özlem Özcan Çelebi

Berna Saylan Çevik

Irem Dinçer

Sabahattin Gündüz

Mert Ilker Hayıroğlu

Burak Hünük

Ersin Kadiroğulları

Muhammed Keskin

Mustafa Kılıçkap

Harun Kundi

Naoki Misumida

Didem 0ğuz

Nazan Özbarlas

Ebru Özpelit

Seçkin Pehlivanoğlu

Bahar Pirat

George C. Priya Doss

Erdoğan Sökmen

Hamza Sunman

Ayşe Sülü

Esin Şenol

Halil lbrahim Tanboğa

Yelda Tayyareci

N. Kürşad Tokel

Serkan Ünlü

Çağrı Yayla

Samet YIImaz

Hikmet Yorgun

Genco Yücel

Cafer Zorkun

\section{Original Investigations}

Comparison of NOACs and warfarin in octogenarians with NVAF: Single tertiary center

Arzu Neslihan Akgün et al.; Ankara-Turkey

Acute ECG changes after cryoballoon ablation

Abdulkadir Uslu et al.; Istanbul-Turkey

Severe right ventricular hypertrophy in hypertrophic cardiomyopathy

Xueqi Dong et al.; Beijing-China

Left atrial expansion index is associated with recurrent stroke

Shih-Hung Hsiao; Taipei-Taiwan

Clinical analysis of cardiac autonomic ganglion plexus ablation for bradyarrhythmia

Mingliang Shao et al:; Urumqi-China

Arterial stiffness and target organ damage

Duygu Övünç Hacıhamdioğlu et al.; Istanbul-Turkey

Evaluation of percutaneous annuloplasty for treatment of FMR

Suat Görmel et al.; Ankara-Turkey

\section{Case Reports}

Giant pulmonary artery aneurysm caused by sibutramine-associated pulmonary arterial hypertension:

First case in the literature

Barkın Kültürsay et al.; Istanbul-Turkey

Unexpected cause of involuntary muscle movements: Reel syndrome

Görkem Kuş et al.; Antalya-Turkey

Transcatheter aortic valve implantation via the left axillary artery route in a patient with a permanent pacemaker:

The first transaxillary artery route experience with a Meril's Myval ${ }^{\mathrm{TM}}$ transaortic valve in Turkey

Telat Keleş et al.; Ankara-Turkey

Is the increase in eltrombopag dose cause of myocardial infarction?

Edip Can Özgünoğlu et al.; Antalya-Turkey

Acute myocarditis after the second dose of SARS-CoV-2 vaccine: Serendipity or atypical causal relationship? Alberto Cereda et al.; Milan-Italy

Page: 494,523
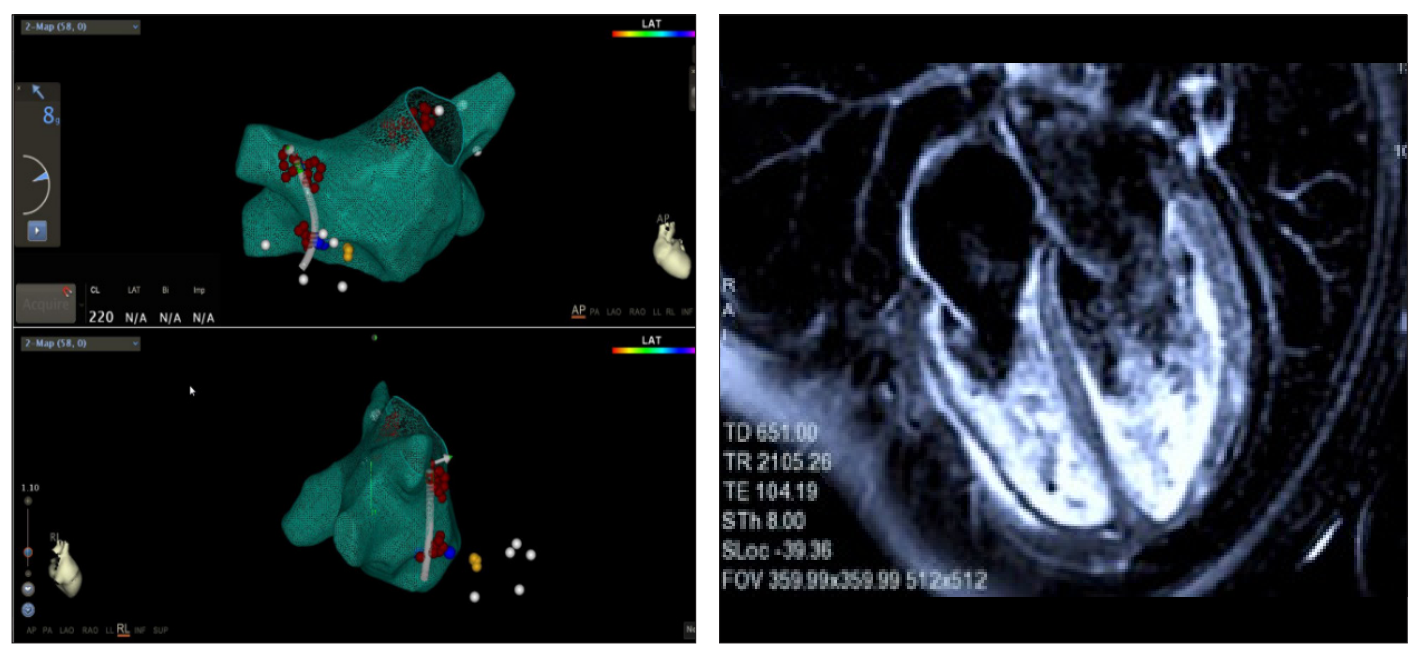


\title{
Editor-in-Chief \\ Prof. Dr. Çetin Erol, Ankara, Turkey
}

\author{
Editors \\ Cem Barçın, Ankara, Turkey Asife Şahinarslan, Ankara, Turkey
}

Adnan Abacı, Ankara, Turkey
Rüçhan Akar, Ankara, Turkey
Nihal Akar Bayram, Ankara, Turkey
Bülent Behlül Altunkeser, Konya, Turkey
Serdal Arslan, Sivas, Turkey
Illyas Atar, Ankara, Turkey
Oben Baysan, Ankara, Turkey
Ahmet Kaya Bilge, Istanbul, Turkey
Hakim Çelik, Şanlıurfa, Turkey
Recep Demirbağ, Şanlıurfa, Turkey
Ş. Remzi Erdem, Ankara, Turkey

Adnan Abacı, Ankara, Turkey Rüçhan Akar, Ankara, Turkey Akar Bayram, Ankara, Turkey Serdal Arslan, Sivas, Turkey lyas Atar, Ankara, Turkey Oben Baysan, Ankara, Turkey Hakim Çelik, Şanlıurfa, Turkey Ş. Remzi Erdem, Ankara, Turkey

\begin{tabular}{ll}
\multicolumn{1}{c}{ Associate Editors } & \\
Illkay Erdoğan, Ankara, Turkey & Murat Özeren, Mersin, Turkey \\
Faruk Ertaş, Diyarbakır, Turkey & Leyla Elif Sade, Ankara, Turkey \\
Sadi Güleç, Ankara, Turkey & Ahmet Temizhan, Ankara, Turkey \\
Ali Gürbüz, Izmir, Turkey & Belma Turan, Ankara, Turkey \\
Gökhan Kahveci, Istanbul, Turkey & Ercan Tutar, Ankara, Turkey \\
Alper Kepez, Istanbul, Turkey & Omaç Tüfekçioğlu, Ankara, Turkey \\
Teoman Kılıç, Kocaeli, Turkey & F. Ajlan Tükün, Ankara, Turkey \\
Ece Konaç, Ankara, Turkey & Taner Ulus, Eskişehir, Turkey \\
Serdar Kula, Ankara, Turkey & Mehmet Uzun, Istanbul, Turkey \\
Selma Metintaş, Eskişehir, Turkey & Aylin Yıldırı, Ankara, Turkey \\
Kurtuluş Özdemir, Konya, Turkey & Mehmet Birhan Yılmaz, Izmir, Turkey
\end{tabular}

Senior Consultant in Biostatistics Kazım Özdamar, Eskişehir, Turkey

\section{Consultant in Biostatistics}

Fezan Mutlu, Eskişehir, Turkey

Previous Editor-in-Chief

Bilgin Timuralp, Eskişehir, Turkey

Ramazan Akdemir, Sakarya, Turkey Levent Akyürek, Göteborg, Sweden Azin Alizadehasl, Tehran, Iran Necmi Ata, Eskişehir, Turkey Saide Aytekin, Istanbul, Turkey Vedat Aytekin, Istanbul, Turkey Ljuba Bacharova, Bratislava, Slovak Republic Luigi P. Badano, Udine, Italy Anzel Bahadır, Düzce, Turkey Adrian Baranchuk, Kingston, Ontario, Canada Murat Biteker, Muğla, Turkey Eugene Braunwald, Boston, MA, USA Cahid Civelek, St. Louis, MO, USA Ali Emin Denktaș, Houston, TX, USA Polychronis Dilaveris, Athens, Greece Firat Duru, Zurich, Switzerland Ertuğrul Ercan, Izmir, Turkey

\section{Editorial Board}

\author{
Okan Erdoğan, Istanbul, Turkey \\ Özcan Erel, Ankara, Turkey \\ Ali Gholamrezanezhad, Tahran, Iran \\ Michael Gibson, Boston, MA, USA \\ Orhan Gökalp, Izmir, Turkey \\ Bülent Görenek, Eskişehir, Turkey \\ Okan Gülel, Samsun, Turkey \\ Sema Güneri, Izmir, Turkey \\ Yekta Gürlertop, Edirne, Turkey \\ Murat Güvener, Ankara, Turkey \\ Cemil İzgi, London, UK \\ Diwakar Jain, Philadelphia, USA \\ Erdem Kaşıkçıoğlu, Istanbul, Turkey \\ Cihangir Kaymaz, Istanbul, Turkey \\ Mustafa Kılıç, Denizli, Turkey \\ Mustafa Kilıçkap, Ankara, Turkey \\ Serdar Küçükoğlu, Istanbul, Turkey
}

Thomas F. Lüscher, Zurich, Switzerland/London, UK Peter Macfarlane, Renfrewshire, Scotland RobertW. Mahley, San Francisco, CA, USA

Giuseppe Mancia, Milan, Italy G.B. John Mancini, Vancouver BC, Canada Anthony De Maria, San Diego, CA, USA

Pascal Meier, London, UK Franz H. Messerli, New York, USA

Sanem Nalbantgil, Izmir, Turkey Navin C. Nanda, Birmingham, AL, USA Yılmaz Nişancı, Istanbul, Turkey Hakan Oral, Ann Arbor, MI, USA Necla Özer, Ankara, Turkey Zeki Öngen, Istanbul, Turkey Mehmet Özkan, Istanbul, Turkey Sotirios N. Prapas, Athens, Greece Fausto J. Pinto, Lisbon, Portugal
Vedat Sansoy, Istanbul, Turkey Raşit Sayın, Trabzon, Turkey Mark V. Sherrid, New York, USA Horst Sievert, Frankfurt, Germany Illke Sipahi, Istanbul, Turkey Richard Sutton, Monaco, Monaco Ahmet Şaşmazel, Istanbul, Turkey S. Lale Tokgözoğlu, Ankara, Turkey Murat Tuzcu, Cleveland, OH, USA Dilek Ural, Istanbul, Turkey Ahmet Ünalır, Eskişehir, Turkey Selma Arzu Vardar, Edirne, Turkey Mehmet Yokuşoğlu, Ankara, Turkey Jose L. Zamorano, Madrid, Spain Wojciech Zareba, New York, USA Yuqing Zhang, Beijing, China

The Owner on behalf of the Turkish Society of Cardiology / Türk Kardiyoloji Derneği adına İmtiyaz Sahibi: Vedat Aytekin Address: Nish İstanbul A Blok Kat: 8, No: 47-48 Çobançeşme Sanayi Cad. No: 11 Yenibosna, Bahçelievler 34196 İstanbul, Türkiye Phone: +90 212221 1730-38 Fax: +90212 2211754 E-mail: tkd@tkd.org.tr Web: www.tkd.org.tr SOCIETY OF Editor-in-Chief Office: Phone: +90 (535) 4614162 Fax: +90 (212) 2211754 E-mail: info@anatoljcardiol.com

$\begin{array}{ll}\text { PAVS } & \begin{array}{l}\text { Publisher } \\ \text { Ibrahim KARA }\end{array} \\ & \text { Publications Director } \\ & \text { Ali ŞAHIN } \\ & \text { Editorial Development } \\ & \text { Gizem KAYAN TEKAÜT } \\ & \text { Deputy Publications Director } \\ & \text { Gökhan ÇIMEN }\end{array}$

Publication Coordinators Irem SOYSAL Arzu YILDIRIM Deniz KAYA Bahar ALBAYRAK Gamze BILGEN Irmak BERBEROĞLU Ebru BOZ
Finance and Administration Zeynep YAKIŞIRER ÜREN

Project Coordinators Sinem Fehime KOZ Doğan ORUÇ Emre KARA
Graphics Department

Ünal ÖZER

Deniz Elif DURAN

Contact

Address: Büyükdere Cad. No: 105/9

34394 Şişli-lstanbul, Turkey

Phone: +90 2122171700

E-mail: info@avesyayincilik.com 


\section{AIMS AND SCOPE}

The Anatolian Journal of Cardiology is an international monthly periodical on cardiology published on independent, unbiased, double-blinded and peerreview principles. The journal's publication language is English however titles of articles, abstracts and Keywords are also published in Turkish on the journal's web site.

The Anatolian Journal of Cardiology aims to publish qualified and original clinical, experimental and basic research on cardiology at the international level. The journal's scope also covers editorial comments, reviews of innovations in medical education and practice, case reports, original images, scientific letters, educational articles, letters to the editor, articles on publication ethics, diagnostic puzzles, and issues in social cardiology.

The target readership includes academic members, specialists, residents, and general practitioners working in the fields of adult cardiology, pediatric cardiology, cardiovascular surgery and internal medicine.

The editorial and publication processes of the journal are conducted in accordance with the guidelines of the International Committee of Medical Journal Editors (ICMJE), the World Association of Medical Editors (WAME), the Council of Science Editors (CSE), the European Association of Science Editors (EASE), the Committee on Publication Ethics (COPE) and the HEART Group.

The Anatolian Journal of Cardiology is indexed in Science Citation Index Expanded, PubMed/MEDLINE, EMBASE, Scopus, EMCare, CINAHL, Gale/ Cengage Learning, EBSCO, DOAJ, ProQuest, Index Copernicus and TÜBITAK ULAKBIM TR Index.

The requirements for submission of manuscripts and detailed information about the evaluation process are available in the published journal and also as 'Instructions for Authors' on the web site (http://www.anatoljcardiol.com).

Statements and opinions expressed in the Anatolian Journal of Cardiology reflect the views of the author(s). All liability for the advertisements rests with the appropriate organization(s). The Turkish Society of Cardiology, the editor-in-chief and AVES do not accept any responsibility for these articles and advertisements.

\section{Subscriptions}

The Anatolian Journal of Cardiology is printed on acid-free paper. Applications for subscriptions should be made to the Editorial Office. The abstracts and full texts of published articles can be accessed free of charge at http://www.anatoljcardiol.com.

\section{Financial support and advertising}

The revenue of the Anatolian Journal of Cardiology is derived from subscription charges and advertisements. Institutions wishing to place an advertisement in the printed version of the journal or on the web page should contact AVES.

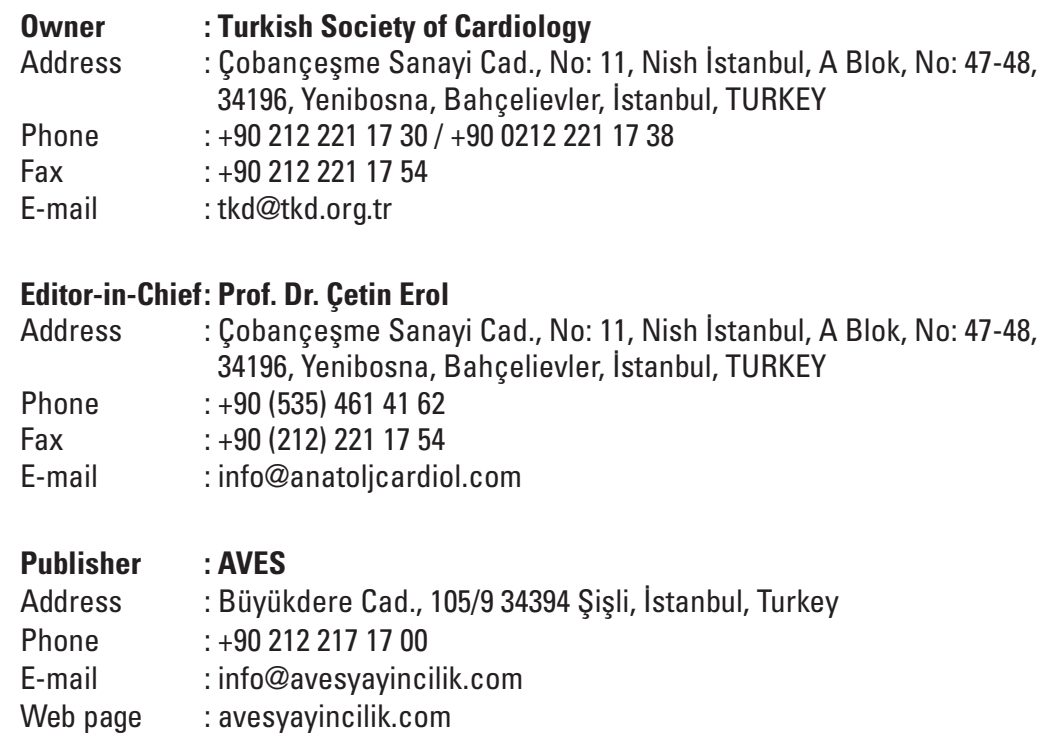




\section{INSTRUCTIONS FOR AUTHORS}

The Anatolian Journal of Cardiology is published in accordance with the principles of independent, unbiased, and double-blinded peer review. It publishes original research related to clinical, experimental and basic sciences on cardiology, editorial comments, reviews covering current issues, educational articles, scientific letters, case reports, letters to the editor, original images, articles on history of medicine and publication ethics, diagnostic puzzles, and interviews deemed appropriate for the purposes and scope of the journal.

The journal evaluates only the manuscripts submitted through its online submission system on the web site http://www.anatoljcardiol.com. Manuscripts sent by other means will not be accepted.

The primary conditions for the acceptance of manuscripts for publication are originality, scientific value and citation potential.

\section{STATEMENTS AND GUIDELINES}

\section{Statements}

- All statements and opinions expressed in the manuscripts published in the Anatolian Journal of Cardiology reflect the views of the author(s). All liability for the advertisements rests with the appropriate organization(s). The Turkish Society of Cardiology, the Editorin-Chief and AVES do not accept any responsibility for articles and advertisements.

- The manuscripts submitted to the journal, except abstracts, presentations, reviews and parts of theses, should not have been accepted and published previously elsewhere in electronic or printed format. Manuscripts evaluated and rejected by other journals must mention any previous submissions and supply reviewer's reports. This will help to accelerate the evaluation process. If the submitted manuscript has been previously presented at a meeting, the name, date, city and country must be specified.

- The authors transfer all copyrights of the manuscript in the framework of national and international regulations to the Turkish Society of Cardiology as of evaluation process. A Copyright Transfer Form signed by corresponding author in order must be submitted to the journal with manuscript. After acceptance of manuscript, all of authors must fill and sign Copyright Transfer form. A separate form for each manuscript should be submitted. Manuscripts submitted without a Copyright Transfer Form will not be accepted. In the case of rejection, all copyrights transfer to the authors again. Authors must confirm that they will not submit the work to another journal, publish it in the original or another language and or allow a third party to use the manuscript without the written permission of the Turkish Society of Cardiology.

- All contents are the authors' responsibility. All financial liability and legal responsibility associated with the copyright of submitted tables, figures and other visual materials protected by national and international laws rest with the authors. The authors take responsibility for any legal proceedings issued against the journal.

- Rejected manuscripts will not be returned except for artwork.

- To clarify scientific contributions and responsibilities and any conflict of interest issues relevant to the manuscript, all parts of the 'Authors' Contribution' form must be completed by the corresponding author and the 'ICMJE Uniform Disclosure Form for Potential Conflicts of Interest' must be completed online by all authors. Both forms should be included in the manuscript at the time of original submission.

Guidelines

- The format of the manuscripts must be in accordance with the ICMJE Recommendations for the Conduct, Reporting, Editing and Publication of Scholarly Work in Medical Journals (updated in December 2014: http://www.icmje.org/icmje-recommendations.pdf).

- The presentation of the manuscripts must be in accordance with international guidelines. CONSORT should be used for randomized trials, STROBE for observational studies, STARD for diagnostic studies, PRISMA for systematic reviews and meta-analyses, ARRIVE for animal studies, and TREND for non-randomized behavior and public health

Ethics studies.

- All manuscripts will be vetted by the Editor-in-Chief's Office for possible plagiarism and duplication. Sanctions will be imposed in accordance with the guidelines of the Committee on Publication Ethics (COPE) and with the principles of the HEART Group when non-ethical issues arise. The authors must obtain the permission of the copyright holder for non-original tables, figures, graphs, images and other visuals.

- The authors should acknowledge and provide detailed information on any contributions in kind and financial support given by any foundations, institutions and firms.

- An ethics committee report prepared in conformity with the WMA Declaration of Helsinki - Ethical Principles for Medical Research Involving Human Subjects and the Guide for the Care and Use of Laboratory Animals is required to be submitted with experimental and clinical studies, drug trial studies and some case reports. Authors may be asked by the Editor-in-Chief's Office for an ethics committee report or similar in other circumstances also. Manuscripts reporting the results of experimental studies must explain in detail all procedures which volunteer subjects and patients have undergone and a statement indicating that consent for the study has been obtained from all subjects should be included in the text. Animal studies should clearly specify how pain or discomfort has been relieved.

\section{PREPARATION AND SUBMISSION OF MANUSCRIPTS}

Manuscript files should be prepared with Microsoft Office Word. The online submission system will direct authors during all stages of submission and provide necessary support for accelerating the submission process. A list of the files that should be supplied through the online submission system is provided below.

\section{Title Page}

2. Main Text

3. Tables, Graphs and Figures

4. Copyright Transfer Form

5. Author Contribution Form

6. ICMJE Uniform Disclosure Form for Potential Conflicts of Interest

\section{Title Page}

Information about the authors and their institutions should not be included in the main text, tables, figures and video documents. Since submitted manuscripts are evaluated by the reviewers through the online system, personal identification is excluded in the interests of unbiased interpretation. Thus, only information about the manuscript as specified below should be included on the title page. For each type of manuscript, it is mandatory to upload a title page as a separate Microsoft Word document through the online submission system. The title page should include the names of the authors with their latest academic degrees, and the name of the department and institution, city and country where the study was conducted. If the study was conducted in several institutions, the affiliation of each author must be specified with symbols. The correspondence address should contain the full name of the corresponding author postal and e-mail addresses, phone and fax numbers. If the content of the manuscript has been presented before, the name, date and place of the meeting must be noted. Disclosure of conflict of interest, institutional and financial support, author contributions and acknowledgments should be included on the title page.

\section{Main Text}

The manuscripts submitted to our journal are classified and evaluated according to the manuscript types stated below. During preliminary evaluation, the editors assess whether a manuscript's format and sub-headings are prepared in accordance with the journal's guidelines. Therefore, it is important that authors check the accuracy of the main text in terms of the following.

\section{A. Manuscript types \\ - Original investigation \\ - Editorial comment \\ - Review \\ - Education \\ - Scientific letter \\ - Case report \\ - Original image \\ - Letter to the editor \\ - Publication ethics \\ - Scientific puzzle \\ - Miscellaneous articles \\ B. References \\ C. Special Terms and Conditions}

\section{A. Manuscript types}

- Original Research

- Title

- Highlights: Each submission should be accompanied by 3 to 5 "highlight points" which should emphasize the most striking results of the study and highlight the message that is intended to be conveyed to the readers. It should be limited to 70 words.

- Structured Abstract: It should be structured with Objective, Methods, Results and Conclusion subheadings and should be limited to 250 words.

- Keywords: This section should contain a minimum of three and a maximum of six items in accordance with Medical Subject Headings (MeSH) terms prepared by the National Library of Medicine (NLM) and should be placed just below the abstract

- Main Text: It should consist of Introduction, Methods, Results, Discussion, Limitations of the Study and Conclusion sections and should not exceed 5000 words excluding the references.

- References: The reference list should be provided following the Main Text. Limiting the number of references to 50 is usually sufficient.

- Tables, Figures and Images: They should be placed below the reference list and numbered according to their consecutive order in the main text.

- Title, Structured Abstract and Keywords should also be provided in Turkish for manuscripts submitted by Turkish authors or from Turkey. However, translations of these sections for manuscripts submitted by foreign authors outside Turkey will be the responsibility of the publisher.

Statistical Analysis: Statistical analysis should be conducted in accordance with the guidelines on reporting statistical data in medical journals [Altman DG, Gore SM, Gardne MJ, Pocock SJ. Statistical guidelines for contributors to medical journals. Br Med J 1983: 7; 1489-93 and Lang T, Altman D. Basic statistical reporting for articles published in clinical medical journals: the SAMPL Guidelines. In: Smart P, Maisonneuve H, Polderman A (editors). Science Editors' Handbook, European Association of Science Editors, 2013.]. The software used for statistical analysis must be described. Data must be expressed as mean \pm standard deviation when parametric tests are used to compare continuous variables. For nonparametric tests, data must be expressed as median (minimum-maximum) or percentiles (25th and $75^{\text {th }}$ percentiles). In advanced and complex statistical analyses, relative risk (RR), odds ratio (OR) and hazard ratio (HR) must be supported by confidence intervals and $p$ values. The outcomes of statistical analyses and interpretation of the results must be in evidence-based scientific language (Editors of Heart Group journals. Statement on matching language to the type of evidence used in describing outcomes data. Anatolian Journal of Cardiology 2012;12:709). 


\section{- Editorial Comment}

Authors are selected and invited by the Editor-in-Chief. This type of manuscript aims at providing a brief commentary on an article published in the journal by a researcher who is an authority in the relevant field or by the reviewer of the article.

- Title

- Main Text: It should not include subheadings and should be limited to 500 words.

- References: The reference list should follow the main text and the number of references should be limited by 15 .

- Abstract, Keywords, Tables, Figures, Images and other visuals are not included in editorial comments.

- The title should also be provided in Turkish for works submitted by Turkish authors or from Turkey. The title of the manuscripts submitted by foreign authors outside Turkey will be translated into Turkish by the Editor-in-Chief's Office.

\section{- Review}

Reviews prepared by authors with extensive knowledge on a particular field, which has been reflected in international literature by a high number of publications and citations, are evaluated. The authors may be invited by the Editor-in-Chief. A review should be prepared in the format describing, discussing and evaluating the current level of knowledge or topic that is to be used in the clinical practice and it should guide further studies.

- Title

- Highlights: Each submission should be accompanied by 3 to 5 "highlight points" which should emphasize the most striking results of the study and highlight the message that is intended to be conveyed to the readers. It should be limited to 70 words.

- Abstract: It should not include subheadings and should be limited to 250 words.

- Keywords: This section should contain a minimum of three and a maximum of six items in accordance with Medical Subject Headings (MeSH) terms prepared by the National Library of Medicine (NLM) and should be provided just below the abstract.

- Main Text: It should include Introduction, other subheadings and Conclusion sections and should be limited to 5000 words excluding the references.

- References: The reference list should be placed just below the main text and the number of references should not exceed 50 .

- Tables, Figures and Images: They should be provided after the reference list according to their order of appearance in the text.

- For reviews submitted by Turkish authors or from Turkey, Title, Abstract and Keywords should also be provided in Turkish. For reviews submitted by foreign authors outside Turkey, translations of these sections will be the responsibility of the publisher.

NOTE: The originality of the visuals included in the reviews should be assured by submission of an accompanying letter by the authors. Appropriate citation should be done for the visuals adapted from previously published sources, in accordance with the original versions of the printed or electronic copies. The written permission obtained from the copyright holder (publisher, journal or authors) should be sent to the Editor-in-Chief's Office.

\section{- Education}

Knowledge confirmed by the results of recent research studies, involved in education at academic level and used in clinical practices should be presented in detail in this type of manuscript.

- Title

- Abstract: It should not include subheadings and it should be limited to 250 words.

- Keywords: This section should contain a minimum of three and a maximum of six items in accordance with Medical Subject Headings (MeSH) terms prepared by the National Library of Medicine (NLM) and should be provided just below the abstract.

- Main Text: It should include Introduction, other subheadings and Conclusion sections and should not exceed 5000 words excluding the references.

- References: The reference list should be provided just below the main text and the number of references should be limited to 50 .

- Tables, Figures and Images: They should be provided after the reference list according to their order of appearance in the main text.

- For educational articles submitted by Turkish authors or from Turkey, Title, Abstract and Keywords should also be provided in Turkish. For articles submitted by foreign authors outside Turkey, the translation of these sections will be carried out by the Editor-in-Chief's Office.

\section{- Scientific Letter}

Manuscripts which announce a new scientific invention, are clinically significant, and are in the form of a preliminary report are accepted for publication as scientific letters.

- Title

- Main Text: It should include Introduction, other subheadings and Conclusion sections and should not exceed 900 words excluding the references.

- References: The reference list should be provided just below the main text and the number of references should be limited to 10.

- Tables, Figures and Images: They should be provided below the reference list according to their order of appearance in the text and should be limited to two.

- Abstract and Keywords should not be included.

- For scientific letters submitted by Turkish authors or from Turkey, the Title should also be provided in Turkish. For letters submitted by foreign authors outside Turkey, the translation of these sections will be carried out by Editor-in-Chief's Office.

\section{- Case Report}

Since a limited number of case reports is published, only reports which are related to rare cases and conditions that constitute challenges in diagnosis and treatment, offer new methods or suggest knowledge not included in books, and are interesting and educational are accepted for publication.

- Title

- Main Text: It should include Introduction, Case Report, Discussion and Conclusion sections and should not exceed 700 words excluding the references.

- References: The reference list should follow the main text and the number of references should be limited to 10 .
- Tables, Figures and Images: They should be provided after the reference list according to their order of appearance in the text and should be limited to two.

- Abstract and Keywords are not included.

- For case reports submitted by Turkish authors or from Turkey, the Title should also be provided in Turkish. For case reports submitted by foreign authors outside Turkey, the translation of these sections will be carried out by the Editor-in-Chief's Office.

NOTE 1: Case reports that include video images have a better chance of publication.

\section{- Original Image}

Impressive and rare images that reflect significant findings based on clinical science, shed light on fundamental mechanisms of diseases, emphasize abnormalities or

introduce new treatment methods are accepted for publication.

- Title

- Main Text: It should not include subheadings and it should be limited to 250 words

- Tables, Figures and Images: They should be provided after the main text according to their order of appearance in the text and should be limited to two.

- Abstract, Keywords and References are not included.

- For original images submitted by Turkish authors or from Turkey, the Title should also be written in Turkish. For images submitted by foreign authors outside Turkey, the translation of this section into Turkish will be carried out by the publisher.

NOTE 1: Those manuscripts with video images have a better chance of publication

NOTE 2: Manuscripts prepared in accordance with original image criteria are published only as an e-page at the journal's website http://www.anatoljcardiol.com.

\section{- Letter to the Editor}

Letters to the Editor aim to discuss the importance of a manuscript previously published in the journal. This type of manuscripts should also include a comment on the published manuscript. Moreover, articles on topics of interest to readers within the scope of the journal, especially on educational issues, can be published in the format of a Letter to the Editor.

- Title

- Main Text: It should not include subheadings and it should be limited to 500 words.

- References: The reference list should follow the main text and the number of references should be limited to five. The volume, year, issue, page numbers, authors' names and title of the manuscript should be clearly stated, included in the list of references and cited within the text.

- Abstract, Keywords, Tables, Figures and Images, and other visuals are not included.

- For manuscripts submitted by Turkish authors or from Turkey, the Title should also be written in Turkish. For manuscripts submitted by foreign authors outside Turkey, the translation of this section into Turkish will be carried out by the publisher.

\section{- Publication Ethics}

These articles include current information on research and publication ethics and also cases of ethical violation.

- Title

- Main Text: It should not exceed 900 words.

- References: The reference list should follow the main text and the number of references should be limited to 10 .

- Tables, Figures and Images: They should be placed after the reference list according to their order of appearance in the text and limited to two.

- Abstract and Keywords are not included.

- For articles submitted by Turkish authors or from Turkey, the Title should also be written in Turkish. For articles submitted by foreign authors outside Turkey, the translation of this section into Turkish will be carried out by the publisher.

\section{- Scientific Puzzle}

Images obtained directly or on operation, visuals revealed through EKG and/or imaging methods, and macroscopic-microscopic anatomical, pathological findings of attentiongrabbing and rare cases can be published. Unlike original images, the diagnosis and outcome of the case and image are hidden at the beginning in diagnostic puzzles. Four multiple-choice questions are prepared. In the following pages of the journal, the correct answer in terms of precise diagnosis and outcome is given with an explanation and didactic images and then discussed. The Editorin-Chief will convert suitable images into the format of a diagnostic puzzle with the authors' permission.

- Title

- Main Text: It should not exceed 500 words

- References: The reference list should follow the main text and be limited to maximum of three.

- Tables, Figures and Images: They should be placed after the reference list according to their order of appearance in the text and should be limited to five.

- Abstract and Keywords should not be included 
- For diagnostic puzzles submitted by Turkish authors or from Turkey, the Title should also be provided in Turkish. For diagnostic puzzles submitted by foreign authors outside Turkey, the translation of this section into Turkish will be carried out by the publisher.

\section{- Miscellaneous}

This type of manuscript covers important events and obituaries.

- Title

- Main Text: It should not exceed 1000 words.

- References: The reference list should follow the main text and the number of references should be limited to 10 .

- Tables, Figures and Images: They should be placed after the reference list according to their order of appearance in the text and should be limited to five.

- Abstract and Keywords should not be included.

- For manuscripts submitted by Turkish authors or from Turkey, the Title should also be provided in Turkish. For manuscripts submitted by foreign authors outside Turkey, the translation of this section into Turkish will be carried out by the publisher.

\section{B. References}

- References should be numbered in the order in which they are cited within the main text.

- Only manuscripts published or accepted for publication should be cited

- Recent publications related to the topic of the manuscript should be reviewed.

- References that are inaccessible and not indexed in any database should not be cited

- The titles of journals should be abbreviated in accordance with (Patrias K. Citing medicine: the NLM style guide for authors, editors, and publishers [Internet]. $2^{\text {nd }}$ ed. Wendling DL, technical editor. Bethesda (MD): National Library of Medicine (US); 2007 - [updated 2011 Sep 15; cited Year Month Day].

- For references with six and fewer authors, all authors should be listed. For references with more than six authors, the first six authors should be listed, followed by 'et al'.

The style and punctuation of the references should be formatted as in the following examples.

Journal: Muller C, Buttner HJ, Peterson J, Roskomun H. A randomized comparison of clopidogrel and aspirin versus ticlopidine and aspirin after placement of coronary artery stents. Circulation 2000; 101: 590-3.

Book Chapter: Sherry S. Detection of thrombi. In: Strauss HE, Pitt B, James AE, editors. Cardiovascular Medicine. St Louis: Mosby; 1974. p.273-85.

Book with Single Author: Cohn PF. Silent myocardial ischemia and infarction. $3^{\text {rd }}$ ed. New York: Marcel Dekker; 1993

Editor(s) as author: Norman IJ, Redfern SJ, editors. Mental health care for elderly people. New York: Churchill Livingstone; 1996.

Conference Paper: Bengisson S. Sothemin BG. Enforcement of data protection, privacy and security in medical informatics. In: Lun KC, Degoulet P, Piemme TE, Rienhoff 0, editors MEDINF0 92. Proceedings of the $7^{\text {th }}$ World Congress on Medical Informatics; 1992 Sept 6-10; Geneva, Switzerland. Amsterdam: North-Holland; 1992.p.1561-5.

Scientific or Technical Report: Smith P. Golladay K. Payment for durable medical equipment billed during skilled nursing facility stays. Final report. Dallas (TX) Dept. of Health and Human Services (US). Office of Evaluation and Inspections: 1994 0ct. Report No: HHSIGOE 169200860.

Thesis: Kaplan SI. Post-hospital home health care: elderly access and utilization (dissertation). St Louis (MO): Washington Univ. 1995.

Manuscripts accepted for publication but not published yet: Leshner Al. Molecula mechanisms of cocaine addiction. N Engl J Med In press 1997.

Epub ahead of print articles: Aksu HU, Ertürk M, Gül M, Uslu N. Successful treatment of a patient with pulmonary embolism and biatrial thrombus. Anatol J Cardiol 2012 Dec 26. doi:10.5152/akd.2013.062. [Epub ahead of print]

Manuscript published in electronic format: Morse SS. Factors in the emergence of infectious diseases. Emerg Infect Dis (serial online) 1995 Jan-Mar (cited 1996 June 5): 1(1): (24 screens). Available from: URL: http:/ www.cdc.gov/ncidodIEID/cid.htm.

\section{Special Terms and Conditions}

- For double-blinded peer-review process, the names of the corresponding author and other authors, their affiliations and any information on the study centres should not be included in any part of the submitted manuscripts and images, except the Title Page.

This information should be added to the relevant section of the online submission system and included in the Title Page.

- Pharmaceutical products should be written with their generic names and brand and company names, city and country should be specified for medical equipment and devices.

\section{Tables, Graphs and Figures}

- Tables, Graphs, Figures and other visuals should be numbered in the order of their citation within the text and names of patients, doctors and institutions should not be disclosed.

- Tables should be prepared in a Microsoft Office Word document using the command 'Insert Table' and inserted at the end of the references in the main text.

- Tables should not be submitted in JPEG, TIFF or other visual formats. For microscopic images, the magnification ratio and staining technique used should be specified in addition to figure legends.
- All visuals should have a high resolution (minimum $300 \mathrm{dpi}$.

The thickness of the lines in graphs should be sufficient to minimize loss of quality if size reduction is needed during the printing process. The width of the graphs should be $9 \mathrm{~cm}$ or $18 \mathrm{~cm}$. Drawings should be performed by professionals. No grey colours should be used.

- Abbreviations should be explained in alphabetical order at the bottom of the tables, graphs and figures

- Roman numbers should be avoided in tables and figures within the text and their titles.

- Decimal numbers used in text, tables and figures should be separated by commas in Turkish sections and by dots in English sections.

- Tables should be easily understandable and should not repeat the data in the main text.

- In addition to the pictures included in case reports and original images, video and movie images are published on the journal's website. These images should be prepared in MPEG format with a maximum size of $2 \mathrm{MB}$. They should be submitted to the journal with the manuscript documents. The names of patients, doctors, institutions and places should be omitted from all documents.

NOTE: All visuals in the manuscripts are printed in black and white without charge. However 300 TL per article must be paid if colour is required. The Editor-in-Chief's Office of the Anatolian Journal of Cardiology should be contacted for payment.

\section{EVALUATION AND PUBLICATION}

- The main text submitted to the journal must be in English. Manuscripts written in other languages are not accepted. Citation potential is higher for manuscripts in English.

- The Editor-in-Chief's Office checks the conformity of the manuscript with the journal's general guidelines before sending it to associate editors and reviewers. Any manuscripts not prepared in accordance with the journal's guidelines will be returned for revision. The evaluation period is limited to 21 days. If revision is requested, authors should submit their revised manuscripts within 24 days. Manuscripts and revisions should be submitted through the online manuscript submission system at the website http://www.anatoljcardiol.com. Manuscripts sent by e-mail will not be accepted.

- Manuscripts are evaluated in accordance with the principles of double-blinded peer review. Of the submitted manuscripts, those considered to be suitable are subjected to preliminary evaluation by the Editor-in-Chief's assistants in terms of style, format, etc. and by the Editor-in-Chief in terms of their content. Manuscripts considered to be scientifically adequate are assigned to four reviewers. These reviewers are independent experts and members of the editorial board who have published internationally on the topic of the manuscript. Research articles, systematic reviews and meta-analyses are also evaluated by the Editor-in-Chief's statistician counsellors in addition to peer review. When needed, the manuscripts are scanned by the Editor-in-Chief's Office using the iThenticate program for determination of plagiarism and non-ethical situations. Also, all manuscripts are reviewed and edited for compliance with the rules of English grammar. All contributing authors of a manuscript accepted for publication are deemed to have accepted the right of editors to make corrections provided that no fundamental change is made to the basic meaning of the original text. Manuscripts not accorded priority for publication by the Editor-in-Chief, Editor, Associate Editors and Referees are rejected.

- The retraction requests of the manuscripts close to the final decision in evaluation process, without any reasonable explanation (not contrary to the Publication Ethics) is considered in the scope of rejection decision. Manuscripts that are not revised and resubmitted within the specified time and fail to notify the journal accordingly will be rejected.

- Once a manuscript is accepted for publication, addition to the author list, removal from the author list and order change cannot be effected.

- Manuscripts accepted for publication are prepared as 'Epub ahead of print articles' and published with an assigned DOI on the journal website http://www. anatoljcardiol.com.

- Information on the latest status of manuscripts submitted for evaluation and other information about the journal are available on the website http://wWw. anatoljcardiol.com. Contact details for the Editor-in-Chief's Office and the publisher are given below.

$\begin{array}{ll}\text { Owner } & : \text { Turkish Society of Cardiology } \\ \text { Address } & : \text { Çobançeşme Sanayi Cad., No: 11, Nish İstanbul, A Blok, No: 47-48, } \\ & 34196, \text { Yenibosna, Bahçelievler, İstanbul, TURKEY } \\ \text { Phone } & :+902122211730 \text { / }+9002122211738 \\ \text { Fax } & :+902122211754 \\ \text { E-mail } & : \text { tkd@tkd.org.tr } \\ \text { Editor-in-Chief: Prof. Dr. Çetin Erol } \\ \text { Address } & : \text { Çobançeşme Sanayi Cad., No: 11, Nish İstanbul, A Blok, No: 47-48, } \\ & 34196, \text { Yenibosna, Bahçelievler, İstanbul, TURKEY } \\ \text { Phone } & :+90 \text { (535) 461 41 62 } \\ \text { Fax } & :+90 \text { (212) } 2211754 \\ \text { E-mail } & : \text { info@anatoljcardiol.com } \\ \text { Publisher } & : \text { AVES } \\ \text { Address } & : \text { Büyükdere Cad., 105/9 34394 Şişli, Istanbul, Turkey } \\ \text { Phone } & :+902122171700 \\ \text { E-mail } & : \text { info@avesyayincilik.com } \\ \text { Web page } & : \text { avesyayincilik.com }\end{array}$




\section{CONTENTS}

\section{EDITORIAL}

Miscellaneous attractive studies

461

Çetin Erol; Ankara-Turkey

\section{ORIGINAL INVESTIGATIONS}

- Comparison of non-vitamin $\mathrm{K}$ antagonist oral anticoagulants and well-controlled warfarin in octogenarians with non-valvular atrial fibrillation: Real-world data from a single tertiary center

Arzu Neslihan Akgün, Emir Karaçağlar, Uğur Abbas Bal, Mehmet Bülent Özin; Ankara-Turkey

- Evaluation of acute alterations in electrocardiographic parameters after cryoballoon ablation of atrial fibrillation and possible association with recurrence

Abdulkadir Uslu, Ayhan Küp, Serdar Demir, Kamil Gülşen, Batur Gönenç Kanar, Mehmet Çelik, Gökay Taylan, Alper Kepez, Taylan Akgün; Istanbul, Edirne-Turkey

- Severe right ventricular hypertrophy in hypertrophic cardiomyopathy: Serious symptoms, complex surgical procedures, and poor prognosis in Fuwai Hospital

Xueqi Dong, Di Zhang, Yi Qu, Xu Meng, Lin Zhao, Yaxin Liu, Xianliang Zhou; Beijing-China

- Left atrial expansion index is associated with recurrent stroke

Shih-Hung Hsiao; Taipei-Taiwan

- Clinical analysis of cardiac autonomic ganglion plexus ablation for bradyarrhythmia: Research protocol for an intervention study

Mingliang Shao, Yaodong Li, Xianhui Zhou, Yanmei Lu, Ling Zhang, Baopeng Tang; Urumqi-China

- Could arterial stiffness be early reversible target organ damage test in childhood hypertension?

Duygu Övünç Hacıhamdioğlu, Özben Ceylan, Aytül Hande Yardımcl; İstanbul-Turkey

Evaluation of percutaneous annuloplasty for treatment of functional mitral regurgitation: A retrospective study Suat Görmel, Salim Yaşar, Serkan Asil, Erkan Yıldırım, Serdar Fırtına, Hatice Taşkan, Mustafa Köklü, Yalçın Gökoğlan, Barış Buğan, Ayşe Saatçi Yaşar, Hasan Kutsi Kabul, Murat Çelik, Uygar Çağdaş Yüksel, Cem Barçın; Ankara-Turkey

\section{CASE REPORTS}

- Giant pulmonary artery aneurysm caused by sibutramine-associated pulmonary arterial hypertension: First case in the literature

Barkın Kültürsay, Berhan Keskin, Ali Karagöz, Özgür Yaşar Akbal, Cihangir Kaymaz; Istanbul-Turkey

- Unexpected cause of involuntary muscle movements: Reel syndrome Görkem Kuş, Göksel Çağırcı, Çağın Mustafa Üreyen, Nermin Bayar, Şakir Arslan; Antalya-Turkey

Transcatheter aortic valve implantation via the left axillary artery route in a patient with a permanent pacemaker: The first transaxillary artery route experience with a Meril's MyvalTM transaortic valve in Turkey Telat Keleș, Özlem Özcan Çelebi, Emrah Uğuz, Kevser Balcı, Engin Bozkurt; Ankara-Turkey

Is the increase in eltrombopag dose cause of myocardial infarction?

Edip Can Özgünoğlu, Nermin Bayar, Şakir Arslan, Muhammed Rıdvan Ersoysal, Rauf Avcı; Antalya-Turkey

- Acute myocarditis after the second dose of SARS-CoV-2 vaccine: Serendipity or atypical causal relationship? 522 Alberto Cereda, Cristina Conca, Lucia Barbieri, Giulia Ferrante, Gabriele Tumminello, Stefano Lucreziotti, Marco Guazzi, Antonio Mafrici; Milan-Italy 


\section{LETTERS TO THE EDITOR}

- Left atrial compression by extracardiac structures: A comprehensive multimodality approach Riccardo Scagliola, Gian Marco Rosa, Italo Porto; Genova, Asti-Italy

- Cerebrovascular ischemic event - what about the coronaries Joseph C. Lee, Alaa Alghamry; Queensland-Australia

\section{E-PAGE ORIGINAL IMAGES}

- Progressive pulmonary stenosis due to huge mediastinal thymoma

Murat Çap, Emrah Erdoğan, Abdurrahman Akyüz, Neşe Kanbal Çap, Erkan Erdur; Diyarbakır, Van-Turkey

- Rare ruptured pulmonary arteriovenous malformation mimicking lung tumor in a girl

Suxuan Liu, Xudong Xu, Yongwen Qin, Xianxian Zhao; Shanghai-China 